The ultimate aim of each country is to engage in all branches of the industry and to attain a balanced degree of activity in each branch.

Several factors, however, determine the status of individual countries and/or units within the industry. The most important of these are the extent to which the indigenous supply of crude petroleum is capable of fulfilling the demand for petroleum products within a country; problems of general industrial organization and the extent and influence of governmental control or assistance. In turn, the degree to which governmental influence is exerted or withheld is based on the particular growth of the industry within each country. Far-reaching governmental control and stringent legislation will be found to operate in those countries where there has arisen progressive lack of balance between indigenous supply and home demand, lack of stabilization of markets through nonparticipation of lesser units, or other economic maladjustments.

\title{
The Bushman Skull
}

\section{$\mathrm{I}^{\mathrm{N}}$} the course of a discussion of the significance of the Bushman skull (Soölogiesa Navorsing v. die Nas. Mus., Bloemfontein, 1, 3-4), Dr. T. F. Dreyer contends that the genus Homo at a very early date evolved along three independent lines-Neanderthal, the Eurasian and the Bushman. The Bushman, in the smallness and orthognathism of the face, the steepness of the forehead, and the flatness of the dorsal profile, shows features, in which it resembles the juvenile skull. It is here suggested that this 'foetalization' (Bolk) is not due to an adult retention of juvenile features, but is a precocious assumption of the adult. This explains the fact that a Bushman baby of about twelve months is already a Bushman, and differs distinctly from the babies of other races, as does the adult Bushman from other adults. This difference is thus due to the projection of adult features into the earlier ontogenetic stages.

The typical orthognathism of the Bushman skull, after a period of prognathism which lasts for some months after birth, is extreme up to six years and then is less pronounced in maturity. This is a result of two growth processes, the peak of jaw formation falling within the foetal period, while the upper face, correlated with the growth of the base of the brain, grows more rapidly during the first six years after birth. The eranial form, with characteristic bulging of the forehead and flatness of the dorsal profile, is due to the differential growth of the roof and floor of the brain; there being a lack of growth of the anterior end of the base, while the roof grows very slowly during foetal life, very rapidly during the first two years after birth, and then keeps pace with the floor of the brain until maturity is reached.

Modern miscegenation with Bantu produces a small brain and a long face (Baralong), but early crosses of Bushman with a Hottentot-like race (Matjes River) produced a large brain with a small face. In both cases the proximate cause appears to be a disturbance in the functioning of the pituitary gland. The sella turcica in the Bush-Bantu is abnormally large - the first case recorded of hypertrophy of the pituitary in an African-while in Bush skulls the sella tureica is abnormally small.

Hybridization with the Bushman would thus seem to set up a disturbance of hormonic control, with the result that one or other set of racial characters becomes exaggerated. It remains to be determined whether the differences between the Bushman and other groups of Homo sapiens are of such a degree of importance that most important physiological disturbances result from hybridization, and are of sufficient weight to demand the separation of the race from $H$. sapiens as a distinct species.

\section{Work of the Rothamsted Experimental Station}

\begin{abstract}
TN studying the annual report for 1935 of the 1 Rothamsted Experimental Station*, it is impossible not to be impressed by the number and value of the experiments carried out at this institution in co-operation with various bodies and individuals. If the British farmer and his trading associates are averse to co-operation in commerce, they have not proved to be so in the field of research directed from Rothamsted. One of the fruits of bringing together producer and expert buyer has been progress in the direction of understanding 'quality', as applied to some agricultural products.

A series of fertilizer experiments, carried out with the help of the sugar-beet factories, and planned at the Statistical Department at Rothamsted, has the object of putting the manuring of this crop on a

* Rothamsted Experimental Station: Lawes Agricultural Trust. Report for 1935. Pp. 279. (Harpenden : Rothamsted Experimental Station, 1936.) $28.6 d$.
\end{abstract}

sound and more accurate basis. Trials carried out in Great Britain indicate that this crop does not give the response to various manures that might be expected from Continental experience. In the trials directed from Rothamsted, not only is the effect of fertilizers carefully assessed, but also an elaborate examination of the soil is in progress, in order to correlate soil properties and fertilizer responses. This erop is also the subject of trials at Rothamsted and Woburn, arranged under the ægis of the Ministry of Agriculture and of the sugar-beet factories. These trials are designed to measure the effects of spacing, and of sulphate of ammonia applied at different spacings; the results at both centres indicate that nitrogen produces a greater effect in the narrower rows.

Useful information was gathered from conferences of growers of malting barley; these took the form 
of exhibitions of samples sent from various parts of the country, and valued by the Barley Valuation Committee of the Institute of Brewing. One of the most interesting facts gleaned is that the results of the experiments made by Rothamsted in the last ten years on the manuring of barley have passed into practice; these results indicated that barley is not a starvation crop, and that, provided the danger of lodging is kept in mind, the crop repays manuring.

The expanding acreage of vegetable crops grown in Great Britain is reflected in the increasing attention given them in the Rothamsted scheme of experiments. The expansion in this branch of work was made possible by the investigation into the value of dried poultry manure, put in hand by the Ministry of Agriculture and controlled from Rothamsted. Although the standard errors proved to be rather higher than the average of large-scale root-crop trials, a number of statistically significant fertilizer effects were found for some crops. More work was done on Brussels sprouts than on other crops. Comparing poultry manure with sulphate of ammonia providing the same amounts of nitrogen, the results indicate that, in the more favourable growing season of 1935 , as compared with 1934, sulphate of ammonia proved more effective. Another interesting feature is that the manurial responses showed up more in the first pickings-an important consideration in the marketing of this crop.

The report has also something of interest for hill farmers. In the Bacteriological Department, the work on clover organisms continues, and it appears that the soils of certain hill districts contain harmful strains that do not themselves benefit the clover plant, and also prevent most beneficial strains from forming nodules. Some beneficial strains, however, can overcome the harmful effects of the bad strains, and enable the plant to make normal growth. Promising results have been obtained from experiments on the inoculation of these beneficial strains into soils containing the harmful ones.

The Report includes a review by Dr. W. Brenchley of thirty years' work of the Botanical Department (1906-36). The problems tackled by this Department have been many and varied. The work on boron in relation to plant growth is one of many interesting landmarks in this survey. A chance observation directed attention to the possibility that this element might be essential for plant growth, and it was established conclusively by later work that boron is essential for the growth of many plants, the meristematic tissues being affected in its absence. Dr. Brenchley is perhaps best known in the agricultural world for her researches on weed eradication, work that demanded a number of surveys to ascertain how far weed species, or groups of these, are associated with particular soils or crops.

The survey concludes with an account of the work on the Park grass plots, in which various aspects of grassland management have been studied, such as the influence of season and manuring upon the botanical composition of the herbage from year to year.

\section{Separation}

$\mathrm{A}^{\mathrm{N}}$ N interesting report by G. Champetier (Bull. Soc. Chim., (5), 3, 1701; 1936) deals with the separation of the isotopic forms of elements.

The proportion of the isotopes in an isotopic mixture is very variable. In hydrogen, the atomic ratio is ${ }^{3} \mathrm{H}:{ }^{2} \mathrm{H}:{ }^{1} \mathrm{H}=7 \times 10^{-10}: 1 / 5750: 1$; bromine is a mixture of approximately equal parts of ${ }^{79} \mathrm{Br}$ and ${ }^{81} \mathrm{Br}$. Apart from the well-known case of the isotopes of lead produced by the radioactive changes of uranium $\left({ }^{206} \mathrm{~Pb}\right)$ and thorium $\left({ }^{208} \mathrm{~Pb}\right)$, slight differences in the atomic weights of different specimens of natural elements have been found. A difference of 0.000108 in atomic weight between atmospheric oxygen and oxygen from the water of Lake Michigan has been reported. Small differences in density of water from the surface and from the depths of the sea in various localities are probably due to separation of light and heavy water by gravity. The first quantities of water collected in rain are heavier than the following, whilst snow and glacier water is lighter than ordinary water. These separations are due to differences in vapour pressure and melting point. Water from the wood or dry leaves of a tree is heavier than normal water. All these differences are very slight.

The artificial separation of isotopes has been achieved in various ways. Neon has been separated by fractional diffusion; mercury, zinc, potassium and chlorine (as hydrochloric acid) by distillation at very low pressure; minute quantities of the lithium isotopes, ${ }^{8} \mathrm{Li}$ and ${ }^{7} \mathrm{Li}$, and more appreciable amounts of the potassium isotope, ${ }^{39} \mathrm{~K}$, by the mass-spectro-

\section{of Isotopes}

graph ; and neon, hydrogen, water, ammonia, carbon tetrachloride and oxygen by fractional distillation.

The diffusion method gives better results. If $x_{0}$ and $y_{0}$ are the volumes of the two constituents in the original mixture, and $x$ and $y$ the volumes remaining after diffusion, the enrichment coefficient $r=\frac{y}{y_{0}} \div \frac{x}{x_{0}}$ is related to the isotopic masses $m_{1}$ and $m_{2}$ by the equation

$$
r=a \sqrt{V_{0} / V}
$$

where $a=\left(m_{1}+m_{2}\right) /\left(m_{1}-m_{2}\right) ; V_{0}=x_{0}+y_{0} ; V=x+y$. The values of $a$ for $\mathrm{HD}$ and $\mathrm{H}_{2}$ is 5 , for neon 21 , and for ${ }^{18} \mathrm{O}^{16} \mathrm{O}$ and ${ }^{18} \mathrm{O}^{18} \mathrm{O}, 33$. The diffusion method has been particularly used by Hertz, who has used batteries of porous clay tubes in series, and also by diffusion into mercury vapour of the pumps cir. culating the gas. In the first method, pure ${ }^{20} \mathrm{Ne}$ has been obtained, and in 8 hours l c.c. of pure $D_{2}$ from a mixture containing only 1 in 1000 of $\mathrm{D}_{2}$. Recently, a partial separation of the carbon isotopes ${ }^{12} \mathrm{C}$ and ${ }^{13} \mathrm{C}$ has been achieved by diffusion of methane. Diffusion of hydrogen and deuterium through heated palladium has also been used.

The electrolytic method is the one most successfully used in the separation of hydrogen and deuterium from water. A slight separation of the oxygen isotopes is also effected, but it has been calculated that, to obtain 1 c.c. of $\mathrm{H}_{2}{ }^{18} \mathrm{O}$ by this process, it would be necessary to electrolyse more water than is found on the surface of the earth. In an attempt to separate the tritium isotope, ${ }^{3} \mathrm{H}$, from water, 75 tons of water 